\title{
O PRAGMATISMO E SUA PRESENÇA NA FILOSOFIA, NA EDUCAÇÃO, NA RELIGIÃO E NA POLÍTICA
}

CARVALHO, Isaar Soares de

RESUMO: O presente artigo dedica-se a expor aspectos teóricos e éticos da visão pragmática da realidade, demonstrando a sua presença na história da Filosofia, simultaneamente examinando as suas relações com a instrumentalização da razão na cultura ocidental, especialmente quanto às suas consequências no ensino. Neste sentido, a hipótese de estudo foi a de que se verifica na educação certa prioridade ao lucro e aos resultados práticos, em detrimento às questões humanistas. A cobertura metodológica desta investigação faz o pensamento transitar pela produção intelectual que acura o teor das relações entre os estatutos do Pragmatismo, da Religião e da Política. Por resultados pretendidos, esperávamos poder demonstrar, em síntese, como a Religião seria vista de forma instrumental em nossa cultura, ao deixar o culto ao sagrado à parte, voltando-se ao ofício do negócio lucrativo, difundido por falsos profetas, posicionando politicamente as igrejas como fonte de votos nas disputas eleitorais, ainda que servindo a políticos que neguem a eficácia da fé que os venha a eleger.

PALAVRAS-CHAVE: Pragmatismo, educação, religião, política

ABSTRACT: This article is dedicated to exposing theoretical and ethical aspects of the pragmatic view of reality, demonstrating its presence in the history of philosophy, while examining its relations with the instrumentalization of reason in Western culture, mainly in relation to its consequences in teaching. In this sense, the study hypothesis was that there is a certain priority in education to profit and practical results, to the detriment of humanist issues. The methodological coverage of this investigation makes the thought move through the intellectual production that refines the content of the relations between the statutes of Pragmatism, Religion and Politics. For intended results, we hoped to be able to demonstrate, in summary, how Religion would be seen in an instrumental way in our culture, by leaving the cult of the sacred aside, turning to the business of profitable business, spread by false prophets, positioning the churches politically as a source of votes in electoral disputes, although serving politicians who deny the effectiveness of the faith that will elect them.

KEYWORDS: Pragmatism, education, religion, politics

\footnotetext{
${ }^{1}$ Doutor em Filosofia (UNICAMP). Pós-Doutor em Letras (USP). Docente do Departamento de Ciências Humanas da UEMG - Universidade do Estado de Minas Gerais - Unidade Frutal.
} 


\section{A VISÃo PRAGMÁtICA DA REALIDADE NA HISTÓRIA DA FILOSOFIA}

Em relação à cultura ocidental é necessário reconhecer que, a despeito de toda a sua produção científica e filosófica, o que per se nos faria entende-la pelo viés da abstração pura, na realidade, conduz o raciocínio em direção diversa, isto é, ela, a cultura ocidental, é efetivamente pragmática.

Quero dizer com isso que, em nossa cultura, temos uma sequência que mostra, de um lado, a preocupação com o conhecimento e com o domínio da natureza, principalmente a partir das ideias de Francis Bacon, culminando com os ideólogos do progresso dos séculos XVIII ao XIX e com a produção nos moldes capitalistas e, de outro lado, emerge o continuum de uma crítica da instrumentalização da razão, com base na apreciação da economia política feita por Marx e Engels, retomada pela "Escola de Frankfurt", especialmente em relação ao esclarecimento e à emancipação do homem.

Ao longo da História tivemos um trabalho profundo de julgamento da razão técnica e da transformação do homem em mero instrumento de trabalho, especialmente com as obras de Marx e Engels, as quais se tornaram um paradigma da luta de classes e da defesa da emancipação do trabalhador diante da dominação imposta pelo modo de produção capitalista.

Igualmente, enquanto essa análise era feita na Europa, desenvolvia-se, nos Estados Unidos, através do Pragmatismo, o interesse pela compreensão de um conhecimento que fosse mais voltado para a ação, e que até então era tradicionalmente atribuído às necessidades da cultura norte-americana de se construir materialmente e de se autoafirmar politicamente.

Se observarmos a história da Filosofia, no entanto, encontraremos posturas mais voltadas para a ação e para a vontade e outras atitudes com ênfases mais idealistas e intelectualistas desde a Filosofia pré-socrática.

É assim que, na obra do filósofo italiano Ugo Spirito (1896-1979), menciona-se a presença de uma visão mais voltada para a ação em determinadas escolas e períodos filosóficos (SPIRITO, 1945).

De acordo com ele, para Friedrich Von Schiller (1759-1805), "a frase de Protágoras, para quem o homem é a medida de todas as coisas, pode ser 
considerada como o postulado fundamental dos pragmatistas, isto é, como expressão da síntese indissolúvel entre lógica e psicologia" (SPIRITO, 1945, p. 17).

Nesse sentido, é de suma importância recordar a visão pragmática da oratória, examinada e criticada por Platão em dois diálogos, um intitulado Górgias ou a Oratória e outro, que se intitula Protágoras. Enquanto os sofistas ou retores buscavam a persuasão, lançando mão de artifícios da linguagem que aparentavam ser verdadeiros, Sócrates, Platão e Aristóteles adotavam uma visão não instrumental da linguagem.

No entanto, de todo modo, eles também buscavam a persuasão de seu público, servindo-se também da Retórica. Platão, por exemplo, era um artista da palavra, enquanto ao final do "Livro I" da República, o sofista Trasímaco chamou ao próprio Sócrates de sofista, pois ele desqualificava vários argumentos sobre o que era a Justiça, enquanto que ele próprio não definia o conceito aos seus interlocutores. Por sua vez, Platão chegou afirmar que ele era um sofista, porém, ressalvou que ele era "o bom sofista".

Opunham-se os grandes pensadores citados, em dadas circunstâncias, ao fato dos sofistas cobrarem pelo ensino, chegando Sócrates, de maneira extremamente rude, a compará-los a prostitutas, o que não deixa de ser um argumento em busca de persuasão. De todo modo, sempre que enunciamos um discurso, temos um fim em vista, o que mostra o caráter pragmático da linguagem como algo que lhe é natural. É possível que esse caráter não tenha sido melhor expresso do que no título do livro de John Austin: How to do things with words, um título que, em si mesmo, já tem um caráter ilocucionário, e que foi enunciado em forma de slogan.

A respeito do caráter pragmático da linguagem em si, no entanto, não nos deteremos neste artigo. O nosso propósito nesta primeira parte é demonstrar a presença da visão de mundo pragmática em determinados autores da história da Filosofia ${ }^{2}$.

Ainda de acordo com Ugo Spirito, a mudança de interesse de Sócrates, da Física para a Antropologia, especialmente para as questões éticas e

\footnotetext{
2 Tratei da Retórica numa dissertação de Mestrado e numa tese Doutorado em Filosofia, ambas defendidas no IFCH-UNICAMP, disponíveis em http://repositorio.unicamp.br/. Basta procurar pelo nome do autor.
} 
políticas, poderia ser vista como uma pesquisa de interesse pragmático, isto é, voltada para a ação, não no sentido de simplesmente agir ou pensar em função de um resultado ou do lucro, mas sim no sentido de voltar à crítica filosófica para as questões da pólis, isto é, do Estado e da sociedade.

Spirito ressalta, inclusive, que na obra de Albert Schinz (1870-1943) intitulada Anti-Pragmatisme, propõe-se uma analogia entre o Pragmatismo e a Escolástica, a qual é vista pelo citado autor como o "pragmatismo do medievo"3. Nesse sentido, a Filosofia de Aristóteles era vista na Idade Média como prática, em oposição ao idealismo religioso, e a Igreja a condenava como heresia, pois seu estudo poderia provocar a autonomia da razão perante a Revelação, a separação entre os campos da Filosofia e da Teologia, o questionamento da crença em um fim último transcendente do ser humano, a autonomia do político frente ao religioso e a separação completa entre a Igreja e o Estado 4 .

Por outro lado, avançando na História e chegando a Blaise Pascal (1623-1662), verificamos que, em relação à experiência ${ }^{5}$ religiosa, Ugo Spirito afirma que "se tem reconhecido a Pascal como um precursor do Pragmatismo" (SPIRITO, 1945, p. 18).

Observe que o termo "experiência" tem um caráter pragmático, no

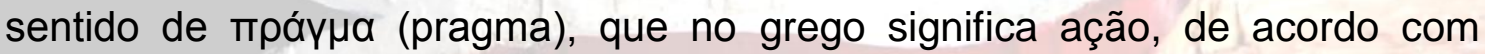
Johannes Hessen.

Também é possível encontrar no pensamento de Kant (1724-1804) uma valorização da interpretação pragmática da realidade, sobre o que Spirito observa, porém, "que a tese, que para Kant se limita ao campo da ética, se

\footnotetext{
${ }^{3}$ SCHINZ, Albert. Anti-pragmatisme: examen des droits respectifs de l'aristocratie intelectuelle et de la democratie sociale. Paris: Felix Alcan, 1909 (Idem, ibid.)

${ }^{4}$ Cf. Marsílio Pádua, O Defensor da Paz (Introdução: Francisco Bertelloni: p. 33-35). Nesse aspecto, é digno de lembrança que no Filme O Nome da Rosa, baseado no livro homônimo de Umberto Eco, o monge George de Burgos, considerando a Poética de Aristóteles perigosa, pelo fato da obra afirmar que o riso é uma virtude, envenenou um exemplar do livro, de tal forma que qualquer pessoa que a lesse, morreria. Em sua ordem monástica era proibido rir, logo, a obra de Aristóteles era considerada perigosa, pois negava esse dogma.

${ }^{5}$ Observe que o termo "experiência" tem um caráter pragmático, no sentido de $\pi \rho \alpha ́ \gamma \mu \alpha$ (pragma), que no Grego significa ação, de acordo com Johannes Hessen. Ver HESSEN, J. Teoria do Conhecimento. S. Paulo: Martins Fontes, 1999 (publicada originalmente em 1925).
} 
converteu, para os pragmatistas, em um postulado gnosiológico"6. Isto é, os pragmatistas convertem a praticidade das ideias no critério para a sua escolha, vendo os juízos como verdadeiros instrumentos, de tal forma que a verdade, em si, pode ficar em segundo plano, passando o pragmatista a adotar os conceitos que derem melhores resultados, independentemente de sua verdade teórica.

No que diz respeito às relações entre o conhecimento e à ação, podemse encontrar os postulados do Pragmatismo também no pensamento de Friedrich Nietzsche (1844-1900). Sua obra vincula-se à filosofia da ação, devido ao valor que confere à vontade e ao corpo na epistemologia e na moral, afirmando o "valor do que é terreno, corpóreo, antiespiritual" e considerando "virtudes todos os comportamentos que dizem sim à vida e ao mundo"7.

Corroborando essa tese, Johannes Hessen (1889-1971) afirma que "o pragmatismo também encontrou defensores na Alemanha" e que, "entre eles e acima de todos, está Nietzsche" (HESSEN, 1999, p. 40). De acordo com Hessen, Nietzsche adotou uma "concepção naturalista e voluntarista da essência humana" 8 . Dessa forma, para Nietzsche, "a verdade não é um valor teórico, mas uma expressão para a utilidade, para a função do juízo que é conservadora de vida e servidora da vontade de poder"9.

Seu pensamento é expresso de forma ainda mais radical quando ele afirma que "a falsidade de um juízo não constitui objeção a esse juízo", mas que "a questão é em que medida ele é promotor da vida, conservador da vida, conservador da espécie e até mesmo, talvez, educador da espécie"10.

Hessen observa, ainda, que apesar de não abandonar a "distinção entre verdadeiro e útil", e de reter "o conceito de verdade no sentido de concordância entre pensamento e ser", Nietzsche afirma que isso jamais é alcançado e que

\footnotetext{
${ }^{6}$ Idem, ibid. Kant reconhece que há situações em que temos de ser pragmáticos, por exemplo, um comandante de um exército tem de tomar decisões prática. Diríamos que ele não pode ficar fazendo muita dialética, mas tem de agir.

${ }^{7}$ ABBAGNANO, N. \& VISALBERGHI, A. História da Pedagogia. Vol. 2, p. $732 \mathrm{~s}$.

${ }^{8}$ Idem, ibid.

${ }^{9}$ Idem, ibid.

${ }^{10} \mathrm{Idem}$, p. $40-41$.
} 
"nossa consciência cognoscente trabalha com representações sabidamente falsas"11.

Em sua análise, Spirito demonstra que "os antecedentes próximos do Pragmatismo são o intelectualismo empírico e o intelectualismo idealista" e que "na exigência de reagir contra toda forma de intelectualismo deve achar-se a razão de ser do Pragmatismo", observando que, enquanto para o intelectualismo "o caráter primordial da verdade consiste em sua objetividade e, portanto, em sua imutabilidade e eternidade [...]". Já, "o Pragmatismo, é a antítese desta posição: a verdade, a realidade mesma em função do sujeito e, portanto, em contínuo devir"12.

O modo de pensar pragmatista, portanto, desenvolveu-se paulatinamente na Europa, tendo o ideal de Francis Bacon de conhecer a natureza para melhor servir-se dela sido reproduzido no pensamento de Augusto Comte, cuja máxima "saber para prever, a fim de poder" era uma palavra de ordem da visão empirista e pragmática da realidade. Comte, que era antimetafísico e anticlerical, idealizador de uma Religião da Humanidade, em oposição ao Catolicismo, tornou-se um modelo do modo de pensar pragmatista.

$\mathrm{O}$ modo de pensar empirista - que tem suas raízes nos séculos $\mathrm{XVI}$ e XVII, especialmente no Novum Organum, de Francis Bacon - se, por um lado, contribuiu para a libertação da pesquisa diante dos dogmas da visão de mundo eclesiástica, por outro lado, com seu ideal de conhecer a natureza para servirse dela culminou numa visão utilitarista da Ciência.

Se o Pragmatismo interpreta o conhecimento e a verdade em relação à experiência, à ação e à utilidade, também no pensamento de Marx e Engels demonstra-se que o conhecimento é voltado para a ação e, portanto, não é uma exclusividade daquela escola. Veja-se, por exemplo, o célebre mote enunciado nas Teses contra Feuerbach: "Os filósofos se limitaram a interpretar o mundo de diversas maneiras, o que importa é transformá-lo"13.

Parece que, nesse assunto, toda a tradição filosófica ocidental está incluída, como se, de fato, os filósofos nada tivessem feito para transformar o

\footnotetext{
${ }^{11}$ Idem, p. 41-42.

${ }^{12}$ Idem, p. 113-114.

${ }^{13}$ MARX \& ENGELS. A Ideologia Alemã. (Teses contra Feuerbach). 7. ed. S. Paulo: Hucitec, 1989.
} 
mundo. Na realidade, Marx elabora uma frase com caráter mais de mobilização do que de teorização. Ele tinha um pensamento que partia da práxis para a ela retornar, o que coincide com a teoria pragmática, de conhecer o que tem valor prático. Difere do Pragmatismo, porém, por sua crítica da luta de classes e por sua utopia revolucionária, a qual, porém, no decorrer da História, mostrou-se indemonstrável, pois nos próprios países comunistas o Estado tornou-se totalitário.

Sua comparação entre as diferentes formas de interpretação do mundo e a sua transformação pode ser comparada, dentro de determinados limites, ao que disse William James sobre as implicações práticas das disputas metafísicas: "O método pragmático nesses casos é tentar interpretar cada noção, traçando as suas consequências práticas respectivas. Que diferença prática haveria, então, para alguém, se essa noção, de preferência àquela outra, fosse verdadeira?"14.

Como se vê, não está em questão, necessariamente, a verdade de uma noção, mas sim, a sua utilidade. Todavia, o conceito de "práxis" de Marx e o conceito de utilidade de James demonstram haver entre si diferenças epistemológicas e ideológicas profundas. Enquanto o conceito de "práxis" faz da verdade uma exigência fundamental, a verdade no Pragmatismo é instrumental, sendo determinada pelos resultados das concepções que forem adotadas. Desse modo, a crítica que a "Escola de Frankfurt" fez, no Século XX, à instrumentalização da razão, pode ser aplicada, dessa forma, ao Pragmatismo.

Por outro lado, ainda que Marx tenha sido prático ao afirmar que "os filósofos se limitaram a interpretar o mundo de diversas maneiras" e que "o que importa é transformá-lo", sua visão era crítica em relação à instrumentalização, não só da razão e da Ciência, mas, acima de tudo, da própria existência humana, a qual ele tem a esperança de emancipar. É nesse sentido, que seu pensamento é retomado pela "Escola de Frankfurt", isto é, como método para a

\footnotetext{
${ }^{14}$ Pragmatismo, Segunda Conferência. Coleção “Os Pensadores”, 1979, p. 17-18 (a publicação original é de 1907).
} 
crítica da tradição positivista e pragmatista, a qual tanta influência exerceu sobre todo o espectro da cultura ocidental.

Enquanto que, no século XIX, na Europa, era feita a crítica dos destinos de uma sociedade regida por uma elite política, industrial e financeira que adotava uma visão utilitarista do conhecimento e das técnicas de produção, nos Estados Unidos, a visão pragmática da realidade era discutida filosoficamente, especialmente como um pensamento voltado para a ação, de acordo com William James.

A cultura norte-americana, de acordo com Dewey e Mead, apresentava "elementos que tenderam a fomentar o caráter e o modo de pensar pragmático" 15 . Nesse sentido, Childs afirma que "na vida do pioneiro, as ideias eram literalmente instrumentos de adaptação", o conhecimento era voltado para o controle do meio circundante ${ }^{16}$.

Descrito por Dewey, Mead e Childs como um fenômeno tipicamente americano, o Pragmatismo, no entanto, é considerado por William James como uma visão de mundo localizável noutras culturas. Seu próprio livro Pragmatismo tem um subtítulo indicativo disso: um novo nome para velhos modos de pensar.

Esse título tão criativo do seu livro, digno de ser considerado como um verdadeiro slogan demonstra que não se deve afirmar que o Pragmatismo seja um modo de pensar tipicamente americano, pois ao longo da história da cultura ocidental observa-se o recurso à visão pragmática da realidade em vários pensadores, conforme já mencionamos.

Quando, pois, os membros do Methaphysical Club rejeitaram as visões teológicas e idealistas da natureza e das instituições sociais, tinham no passado diversas manifestações de sua forma de pensar ${ }^{17}$. O Pragmatismo, assim, do ponto de vista conceitual, é um ponto de chegada ao processo histórico do conhecimento, e não uma descoberta ou algo que foi fundado no Século XIX.

\footnotetext{
${ }^{15}$ CHILDS, John L. Pragmatismo y Educación; su interpretación y crítica. (American Pragmatism and Education: An interpretation and criticism). Buenos Aires: Nova, 1956, p. 16.

${ }^{16}$ Idem, ibidem.

${ }^{17} \mathrm{O}$ citado clube foi fundado em Janeiro de 1872, em Cambridge. Cf.: The Real Metaphysical Club, p. XVIII, obra de autoria de Frank X. Ryan, Brian E. Butler e James A. Good, disponível no books.google. Publicada pela State University of New York, 2019. Consulta realizada em 15/05/2020.
} 
A adoção do Pragmatismo enquanto método de conhecimento, de orientação moral e política da cultura norte-americana, pode ser considerada, também, como uma forma de justificação ideológica do desejo de domínio e de expansão de seu poder ao longo da História. Os pioneiros norte-americanos chegavam a considerar as próprias ideias como instrumentos. Dessa forma, sua violência na ocupação da terra foi disfarçada no discurso do pioneirismo.

$\mathrm{O}$ individualismo presente na sociedade norte-americana, bem como o imperialismo dos Estados Unidos nas relações internacionais, são elementos próprios de uma cultura na qual as ideias, a pesquisa científica, a linguagem, o trabalho, a política, não são interpretados de forma idealista, mas, sim, na perspectiva Pragmática e, assim, se coloca em evidência a pergunta de William James, acima citada: "Que diferença prática haveria para alguém, se essa noção, de preferência àquela outra, fosse verdadeira?". De tal forma que esse método, rejeitando a metafísica e o idealismo, privilegia os resultados práticos do saber, chegando a afirmar que o verdadeiro é aquilo que é útil.

No Brasil, de acordo com João Cruz Costa, os portugueses também foram pragmáticos, adotando as opiniões que, de acordo com a sua visão, poderiam dar os melhores resultados ${ }^{18}$. Isso, vale dizer, melhores de acordo com a sua perspectiva e seus interesses, não com a visão de mundo dos indígenas e dos africanos que depois foram aqui escravizados.

Dessa forma, aquilo que para os portugueses era prático e lucrativo, na realidade era uma forma exacerbada de violência. O pragmatismo português levou até ao limiar do extremo o ato de se buscar uma conciliação entre o domínio e a evangelização dos índios, dois conceitos contraditórios: como, há de se perguntar, então, os invasores dessa Terra puderam falar da redenção, do amor de Deus, da solidariedade aos dominados?

Em relação aos negros, a forma de tratamento dos colonizadores também foi brutal, mais ainda do que em relação aos indígenas, ainda que tivessem sido os negros quem construíram a Igreja de São Francisco, em Salvador - BA, a qual tem uma tonelada de ouro em seu interior.

Um pragmatismo incompreensível esse dos portugueses: adornar com ouro uma igreja usando a mão de obra escrava. Assim, o ensino sobre o amor

${ }^{18}$ Costa, João Cruz. Panorama da História da Filosofia no Brasil. S. Paulo: Cultrix, 1960. 
ao próximo era mera teoria, se tanto, sendo os indígenas e negros tratados como força de trabalho e meios de lucro, não como pessoas. Exageros do pragmatismo português, o qual se deu também nos Estados Unidos.

\section{O PRAGMATISMO E A EDUCAÇÃO}

O Pragmatismo teve grande aplicabilidade no século $X X$ na área da Educação, principalmente por sua proposta de associar o conhecimento à experiência e à conduta humana, substituindo conceitos idealistas e metafísicos pela primazia da experiência, dos interesses da criança e da continuidade do processo de aprendizagem.

Com a precedência do indivíduo e de suas potencialidades no processo educativo, ele passa a ser formado para atuar numa sociedade competitiva para conquistar sua autonomia numa economia que se coloca acima de todos os valores de solidariedade, na qual o homem é o lobo do homem, como cita Hobbes, na obra Do Cidadão (1642).

O Pragmatismo, dessa forma, é uma visão de mundo antiga, porém, no capitalismo ele estimula a ética da concorrência, a qual nos obriga a buscar qualificação e constantes atualizações para sermos inseridos no mercado de trabalho e sobreviver numa sociedade que ainda continua numa guerra que é de todos contra todos, como afirma Hobbes no célebre capítulo XIII, do Leviatã (1651). A partir desse ponto de vista, a própria ética protestante, analisada minuciosamente por Max Weber, tem um caráter pragmático.

A proposta de ensino pragmatista recebe, portanto, a designação de instrumentalismo ou experimentalismo, a qual é admitida pelo próprio John Dewey, filósofo e educador norte-americano. No entanto, essa preocupação, com os fins práticos voltados à educação, evidencia-se já no pensamento de James, para quem a educação, "em resumo, consiste na organização dos recursos do ser humano, na disciplina dos poderes da conduta que lhe permitem subsistir no meio social e físico. Em suma, a educação, tem por fim, organizar hábitos adquiridos e tendências para agir" (JAMES, 1911, p. 18).

William James, que era norte-americano, procurava corroborar essa afirmação, citando o ideal de educação que prevalecia noutros países, 
propondo que "por toda parte, o acordo é para se organizarem as faculdades favoráveis à conduta"19. Disse também que isso era visto com clareza na Alemanha, "onde o fim explicitamente confessado da educação superior é fazer do aluno um instrumento capaz de levar por diante as descobertas científicas" ${ }^{20}$. Reconhece, porém, os limites dos formadores, afirmando que "não possuem, necessariamente, tais especialistas, uma capacidade intelectual muito original", ainda que capazes de, a partir de um procedimento metodológico, acrescentar novas descobertas à área em que pesquisam. $\mathrm{E}$ corrobora, categoricamente, que, quanto aos fins almejados da formação: "Na Alemanha, a pedra de toque para se aquilatar da capacidade de um portador de diploma é a habilidade e que ele dê provas em tais investigações" ${ }^{21}$.

A ética capitalista busca justificativas ideológicas sempre recorrentes, as quais podem alternar posturas em sua forma discursiva. Hoje ela é justificada pela ideologia do neoliberalismo, a qual, dentre outras, adota o Pragmatismo como uma de suas formas de discurso, prescindindo de suas aplicações democráticas, tanto na área do ensino quanto na ética em geral. Dessa forma, ainda que nos moldes burgueses o Pragmatismo defendesse a Democracia, hoje o que está em evidência é simplesmente a instrumentalização, não só da razão e do conhecimento, mas da própria pessoa.

A ideia de John Dewey, da constante renovação dos métodos e da experiência educacional, ainda que tenha sua relevância conceitual, pode ser vista, na atualidade, como uma oportunidade de negócio, visto que a Educação, também, foi transformada numa mercadoria, na qual os cursos são vendidos como produtos, os materiais escolares tradicionais são substituídos pelas tecnologias da informação necessárias para a aprendizagem, as quais se renovam frequentemente e exigem do aluno-consumidor uma atualização de seus instrumentos ou "ferramentas" de trabalho.

Dessa forma, a Escola exerce uma função pragmática, preparando as pessoas para o mercado de trabalho e para a continuidade da cultura e da ética capitalista, sendo ela própria um produto dessa cultura e, de forma dialética, um de seus mais importantes aparelhos ideológicos de manutenção e

\footnotetext{
${ }^{19}$ Idem, p. 19.

${ }^{20}$ Idem, ibidem.

${ }^{21}$ Idem, p. 19-20.
} 
de renovação, sendo ela mesma, agora, um produto intermediário entre os cidadãos e o mercado de trabalho.

\section{PRAGMATISMO, EDUCAÇÃO E CAPITALISMO NO BRASIL}

Em nossa cultura acadêmica vê-se com reserva o Pragmatismo em relação à pesquisa, especialmente na Filosofia e na Sociologia. Noutras áreas, no entanto, como em Comunicação, Ciências Sociais Aplicadas, Educação, Ciências Exatas, Tecnológicas e Biomédicas, e mesmo na Psicologia, o Pragmatismo pode ser adotado em relação à pesquisa e às atividades profissionais, bem como pode influenciar e orientar as ações de muitas empresas. Um exemplo claro pode ser visto na famosa empresa de publicidade e propaganda, chamada DM9DDB que, há alguns anos, adotou o seguinte slogan, claramente pragmático: "Propaganda de Resultado".

Verificamos que o Pragmatismo na Educação é defendido claramente pelo governo federal, de forma tão clara que, de acordo com a Revista Exame, "o Presidente Jair Bolsonaro confirmou, nesta sexta-feira (26/04/20) que o Ministério da Educação estuda fazer cortes nos investimentos em cursos de Humanas nas universidades, principalmente em Filosofia e Sociologia. Em publicação no Twitter, o Presidente afirmou que os repasses serão destinados a projetos que ensinem os jovens a "leitura, a escrita e a fazer contas", para que a sua formação "gere renda para a pessoa e bem-estar para a família"22.

A reportagem afirma, ainda, em relação ao Ministro da Educação, Abraham Weintraub: "Na noite desta quinta-feira (25/04/20), durante transmissão ao vivo pelo Facebook, o Ministro da Educação, Abraham Weintraub (In: O GLOBO, 2020), já havia indicado que faria cortes nessa área. Assim como o Presidente, ele sinalizou que alunos já matriculados não serão afetados. Como justificativa para a decisão, o Ministro deu o exemplo do Japão, que reduziu as verbas dos cursos de Ciências Sociais e Humanas, em 2015". Cita a reportagem, a seguir, as palavras do Ministro, conforme se seguem:

${ }^{22}$ Revista Exame, 26/04/2019: https://exame.abril.com.br/brasil/bolsonaro-sugere-reduzir-verba-paracursos-de-filosofia-e-sociologial. Acesso em 17/05/2020. 
- O Japão, país muito mais rico que o Brasil, está tirando dinheiro público, do pagador de imposto, das faculdades que são tidas como para pessoas que já são muito ricas, ou de elite, como filosofia. Pode estudar filosofia? Pode, (mas) com dinheiro próprio. E o Japão reforça: esse dinheiro que iria para faculdades como filosofia, sociologia, se coloca em faculdades que geram retorno de fato: enfermagem, veterinária, engenharia e medicina (O GLOBO - Abraham Weintraub, 2020).

Prossegue ainda a matéria, afirmando que, "segundo Abraham, é preciso melhorar a 'performance' dos alunos para gerar mais empregabilidade e empreendedorismo no Brasil". Afirmou o Ministro, ainda, que "nossos alunos, no Brasil, não têm o mesmo conhecimento técnico, de sair da faculdade, ter ideias, sacadas e montar pequenos negócios. A gente está trabalhando com uma série de ideias, planos, mas vocês vão ter que esperar um pouquinho", concluiu $^{23}$. E, onde mais o Pragmatismo na Educação poderia estar definido de melhor forma?

Por outro lado, verifica-se a presença do Pragmatismo nas Universidades, de maneira mais acentuada desde a implantação do Exame Nacional de Desempenho dos Estudantes (ENADE), de tal modo que as universidades devem preparar seus alunos não só para o mercado de trabalho, mas, também, para o citado exame, cuja nota média dos alunos participantes é atribuída ao próprio Curso que eles frequentam. Assim, uma boa nota será usada, depois, nas propagandas da instituição, de tal forma que ficou ainda mais claro que a Educação tornou-se um produto para ser levado ao mercado e avaliado pelo consumidor, no caso, o estudante.

No afã de melhorar sua pontuação houve, em 2007, uma instituição em São Paulo - SP, que ofereceu uma premiação em dinheiro aos alunos que obtivessem as melhores notas no ENADE, variando a compensação financeira entre $R \$ 300,00$ e $R \$ 600,00$ (valores em reais brasileiros), conforme reportagem do "Portal G1", que dizia: "Faculdade oferece prêmio dinheiro ao aluno que tirar boa nota no ENADE. O valor oferecido foi de $R \$ 300$ a $R \$ 600$, para a prova deste domingo. Iniciativa divide estudantes e especialistas em educação" (PORTAL G1, 2020).

\footnotetext{
${ }^{23}$ Revista Exame, op. cit.
} 
Essas situações demonstram que houve uma instrumentalização ainda maior da Universidade, e a formação dos alunos passou a exigir uma espécie de pós-vestibular, ficando a Graduação como uma espécie de preparação para um Juízo Final, tanto para eles quanto para a instituição na qual estudam.

O Pragmatismo presente nesse processo torna-se ainda mais evidente, porque as notas desse exame são utilizadas pelo mercado de trabalho como critério de seleção de pessoal, o que evidencia a cada ano o predomínio da mentalidade pragmática da Universidade. É uma corrente, cujos elos são inescapáveis, e nela estamos presos, e por mais críticos que sejamos, acabamos enredados na preparação para o mercado de trabalho, salvo com as exceções das poucas pessoas que estudam pelo prazer do conhecimento - é o triunfo do Pragmatismo.

$O$ advento de novas tecnologias foi saudado por muitos educadores como revolucionário no processo pedagógico e a atualização tecnológica tornou-se necessária para as instituições de ensino, professores e alunos. No entanto, com ela se apresenta um discurso publicitário, o qual é enunciado tanto pelas indústrias quanto pelo comércio, pelo governo e pela própria Academia, e parte considerável das verbas das universidades, tanto públicas quanto privadas, é destinada a pesquisas e renovações nas áreas de tecnologia, ficando a análise da cultura, incluindo as próprias mudanças tecnológicas e do destino da civilização relegadas a um lugar secundário.

A visão pragmática do ensino e da Ciência, dessa forma, fortalece a ideologia da instrumentalização da razão, destinando maior investimento às áreas do saber que são fomentadoras da ação e do lucro. Assim, o conhecimento enquanto descoberta desinteressada, pelo simples prazer de saber, foi substituída pela visão da Ciência como um instrumento para o domínio da natureza e das diversas técnicas de trabalho, bem como da própria sociedade.

Isso, porém, resulta em benefício apenas de pequena parte da humanidade, pois a exclusão social aumenta a cada dia, sendo os resultados da Ciência, especialmente da área da Saúde, de acesso limitado para a maioria da população, de tal forma que não bastam os avanços científicos e tecnológicos para que tenhamos uma melhor qualidade de vida, mas é 
necessário que tenhamos também a adoção da "ética da reverência pela vida", como ensinou Albert Schweitzer.

Devido à valorização do conhecimento associado ao resultado e ao lucro, das relações entre a Ciência, a produção e o mercado, a busca pelo conhecimento tornou-se parte da competição presente na sociedade capitalista, desde os indivíduos entre si até às relações entre as nações, haja vista que durante as duas Grandes Guerras do Século XX, houve um acentuado desenvolvimento científico e tecnológico, de tal forma que podemos afirmar, parodiando o "Eclesiastes", que, dependendo das circunstâncias históricas, quem aumenta em Ciência aumenta em poder ${ }^{24}$.

Ainda em relação ao Brasil, o Pragmatismo na Educação pode ser verificado claramente com a implantação de Escolas Técnicas, sejam elas federais, estaduais, municipais ou particulares, bem como de Institutos Tecnológicos. Talvez, o mais famoso dentre eles, seja o ITA (Instituto Tecnológico da Aeronáutica), além dos Institutos Técnicos Federais espalhados pelo País, de tal modo que é possível dizer que chegamos a uma cultura da Tecnocracia. Assim, a Ciência é instrumentalizada de acordo com os interesses econômicos, políticos e bélicos, de tal forma que, com o passar do tempo, chegou-se a uma situação em que saber é poder, como já afirmara Augusto Comte: "Saber, para prever, a fim de poder".

A instrumentalização do conhecimento na Universidade brasileira atual é evidente, especialmente quando se constata que ela tem sido um local em que predomina a mentalidade da habilitação para o trabalho, ficando disciplinas como a Filosofia, a qual, para Descartes, é comparável a uma árvore do conhecimento. A Sociologia e outras disciplinas já citadas, também são postas em lugares secundários nessa Epistemologia Pragmática que aqui predomina. Assim, mesmo que desconheçam William James, há professores que cumprem o que ele considerava, em 1911, ser necessário exigir de alguém diplomado: "O fim explicitamente confessado da educação superior é fazer do aluno um instrumento capaz de levar por diante as descobertas científicas" 25 .

\footnotetext{
${ }^{24}$ O autor do "Eclesiastes", Livro sapiencial do Antigo Testamento, parece ter uma visão pessimista do conhecimento, pois afirma que "o muito estudar enfado é da carne", que "na muita sabedoria há muito enfado" e que "o que aumenta em ciência aumenta em trabalho".

${ }^{25}$ William James, Palestras Pedagógicas, op. cit., p. 20 (Os grifos são nossos).
} 


\section{A PRESENÇA DO PRAGMATISMO NA BÍBLIA}

A Bíblia apresenta várias situações em que se demonstram a importância do resultado, nas quais podem ser vistas comparações com o Pragmatismo, porém, sem qualquer conotação ética negativa em relação à busca por resultados. Vejamos três casos.

Em primeiro lugar, a própria Palavra de Deus busca um resultado, como diz o profeta Isaías: "Assim como descem a chuva e a neve dos céus e para lá não tornam, sem que primeiro reguem a terra, e a fecundem, e a façam brotar, para dar semente ao semeador e pão ao que come, assim será a palavra que sair da minha boca; não voltará para mim vazia, mas fará o que me apraz, e prosperará naquilo para que a designei" (ISAÍAS, 55:11).

O mesmo texto fala claramente sobre o bom uso do dinheiro e sobre uma atividade laboriosa que dê resultado: "Por que gastais o dinheiro naquilo que não é pão, e o vosso suor, naquilo que não satisfaz?" (ISAÍAS, 55:2).

Em segundo lugar, a respeito do Rei Davi, que estava faminto, juntamente com seus soldados, deu-lhes a comer dos pães da proposição o próprio Cristo, no que se reconheceu que era mais útil alimentar a esses homens, bem como ao próprio Davi, do que manter os pães consagrados no altar, mas sem exercer a sua utilidade principal, que era a da alimentação. Por isso, Cristo se referiu a essa atitude de Davi, a qual parecia ser um sacrilégio, tomando-a como exemplo para justificar o fato de seus discípulos colherem espigas num dia de sábado, o que, até então, era proibido na Lei de Moisés. Porém, o que seria mais útil: obedecer à Lei e ficar com fome ou desobedecêla e alimentar-se.

Foi assim que Cristo, em resposta aos seus críticos, disse: "Nunca lestes o que fez Davi, quando se viu em necessidade e teve fome, ele e os seus companheiros? Como entrou na Casa de Deus, no tempo do sumo sacerdote Abiatar, e comeu os pães da proposição, os quais não era lícito comer, senão aos sacerdotes, e deu também aos que estavam com ele? (MARCOS, 2:25-27). 
Em terceiro lugar, o apóstolo Paulo reconheceu a importância da pregação do Evangelho, mesmo que esta fosse feita por inveja ou porfia. Ele raciocina pensando nos frutos da pregação, isto é, em seu resultado, ao dizer:

Alguns, efetivamente, proclamam a Cristo por inveja e porfia; outros, porém, o fazem de boa vontade; estes, por amor, sabendo que estou incumbido da defesa do evangelho; aqueles, contudo, pregam a Cristo, por discórdia, insinceramente, julgando suscitar tribulação às minhas cadeias. Todavia, que importa? Uma vez que Cristo, de qualquer modo, está sendo pregado, quer por pretexto, quer por verdade, também com isto me regozijo, sim, sempre me regozijarei (FILIPENSES, 1:15-18).

Torna-se evidente que, para ele, o que importava era o fato do nome de Cristo ser proclamado, "quer por pretexto, quer por verdade", pois ele sabia da eficácia da Palavra de Deus, a qual, sendo enunciada, não volta para ele vazia.

O Apóstolo Paulo pode ser considerado o pai do pragmatismo missionário, pois afirmou: "[...] Eu procuro, em tudo, ser agradável a todos, não buscando o meu próprio interesse, mas o de muitos, para que sejam salvos" (I CORÍNTIOS 10:33). Tendo como objetivo ou resultado a salvação, ele se esmera ainda mais, ao ponto de dizer: "Fiz-me fraco para com os fracos, com o fim de ganhar os fracos. Fiz-me tudo para com todos, com o fim de, por todos os modos, salvar alguns" (I CORÍNTIOS 9: 22).

É provável que o apelo de Paulo a César, quando de sua audiência diante do Rei Agripa, na cidade de Cesareia, tenha sido feito porque ele tinha como objetivo a evangelização da Capital do Império. O Rei, no entanto, não entendendo seus objetivos e sua vocação, disse a Festo, governador da província: "Este homem bem podia ser solto, se não apelasse para César" (AT, 26,32). Ao mesmo tempo, ele foi pragmático ao apelar para César porque, se fosse solto por Agripa e permanecesse em Cesareia, poderia ser morto pelos judeus que o perseguiam.

Dessa forma, a atitude pragmática pode ser uma estratégia para fins elevados, como a preservação da vida e a pregação do Evangelho. 


\section{O PRAGMATISMO NAS RELAÇÕES ENTRE A RELIGIÃo E A POLÍTICA}

O maior problema nas posturas pragmáticas em relação à religião, especificamente em relação ao Cristianismo, em suas diferentes Igrejas e denominações, encontra-se quando se buscam resultados prescindindo-se da ética.

Atualmente presenciamos tanto a realização de interpretações da Bíblia com bases hermenêuticas relevantes quanto nos defrontamos com interpretações oportunistas e superficiais, numa espécie de religião de resultados, presente especialmente em igrejas neopentecostais, algumas presentes na grande mídia, como a Universal, a Mundial e a Internacional da Graça de Deus, que exploram a fé e os símbolos religiosos de forma mercadológica.

Observe o leitor que os próprios nomes dessas Igrejas são pretensiosos em relação à sua abrangência: Universal, Mundial, Internacional, e recentemente surgiu, na Bahia - BA, a Igreja Global. Tais instituições adotam um discurso que promete bênçãos como a cura, a colocação no mercado de trabalho, o pagamento de dívidas, a compra de imóveis etc., e conseguem arrecadar ofertas mesmo de pessoas em explícita situação de escassez financeira, praticando técnicas persuasivas e treinando seus obreiros e pastores para tal.

Quando da morte do ator Norton Nascimento, a mídia noticiou uma afirmação dele em relação a Sônia Hernandes, Bispa da Igreja Renascer em Cristo. Em meio a uma entrevista, o ator afirmou: "[...] Também, se não quiser ver a peça é só ver a Bispa Sônia pregar, viu?". E afirmou ainda que, quem ouvi-la, "além de ser abençoado, ainda vai aprender uma coisa maravilhosa. A Bispa Sônia pregando é aula de teatro"26.

Por outro lado, do ponto de vista das relações entre política e religião, pelo viés da necessidade prática, os locais simbólicos da Igreja Católica são procurados por personagens da Política, como o Santuário de Aparecida do

\footnotetext{
26 "Bispa Sonia pregando, é aula de teatro". In: https://www.youtube.com/watch?v=pl-biB2AJoA.
} 
Norte, o qual foi visitado pelo Presidente Jair Bolsonaro, que é católico e fez questão de visitar o santuário, porém não deixou de recorrer a líderes evangélicos neopentecostais em busca de apoio eleitoral.

De tal forma que, tanto ir a Aparecida quanto levar ao seu palanque, em Brasília, o Bispo Edir Macedo, ou subir ao palco da "Marcha para Jesus", com os religiosos Estevam e Sônia Hernandes, são atitudes pragmáticas, isto é, estão em busca da crença e da adesão do eleitorado.

Sendo assim, a performance dos atores políticos visando o resultado é múltipla, levando até mesmo pessoas como Fernando Hadadd e Manuela D'Ávila, do PC do B, declaradamente ateus, a frequentarem uma Missa no Jardim Ângela, em São Paulo - SP, em 12 de Outubro de 2018, dia da Padroeira do Brasil.

Presenciei uma visita do Engenheiro José Filippi Júnior, que foi Prefeito de Diadema - SP, por três mandatos, à igreja da "Assembleia de Deus", do Bairro do Taboão, na referida cidade. Ele foi pedir uma oração e se ajoelhou no altar, enquanto o Pastor Ihe impunha as mãos. Não se pode negar o seu respeito, sua humildade e a sua piedade, mas de todo modo a sua presença ali não deixou de exercer influência sobre a comunidade, posto que mesmo indiretamente, a sua atitude teve um caráter discursivo e persuasivo.

O Ex-Presidente Fernando Henrique Cardoso, que se declarou ateu quando concorreu à Prefeitura de São Paulo - SP, nos anos 1990, perdeu muitos votos por ter feito essa declaração, não levando em conta o caráter ilocucionário da linguagem. No dia seguinte à sua afirmação, Jânio Quadros, que também era candidato, mandou colocar nas ruas cartazes com o slogan: "Cristão vota em Jânio", aproveitando a oportunidade discursiva e ganhando muitos votos, vindo a eleger-se. Percebem o pragmatismo presente no discurso? Não importa a sua verdade.

Depois dessa experiência, Fernando Henrique Cardoso, já na Presidência da República, chegou a visitar o Papa em Roma, numa breve audiência. O mesmo homem que disse ser ateu visitou o Vaticano, pois essa atitude era importante para a redenção de sua imagem diante dos eleitores cristãos após a sua negação do nome de Deus. 
Em reportagem da "Folha de S. Paulo", afirma-se que, "ao trocarem presentes (FHC ganhou um livro sobre as obras de Michelangelo na Capela Sistina, e o Papa, uma imagem de madeira de Sant'Ana, feita no século XVIII, na região mineira de Paracatu), os dois conversaram, em português, sobre 0 Brasil e outros países de língua portuguesa"27. Agora, imaginemos que situação esta, um sociólogo e político que se confessou ateu doar uma imagem de Sant'Ana, para o Sumo Pontífice? Coisas do pragmatismo político e dos atos de linguagem em busca da persuasão do eleitorado.

Notemos, também, uma afirmação oportunista do Ex-Presidente Lula, por ocasião da comemoração do dia de "Primeiro de Maio", em 1993, na Praça da Sé, em São Paulo - SP: "O vermelho da bandeira do PT significava o sangue de Cristo" $^{28}$. Para um partido que tem em suas origens ideológicas uma visão de mundo materialista e ateísta, essa afirmação torna-se sem sentido, quer teológico, quer social, quer político, não passando de uma oportunidade para a manipulação da plateia através do discurso. Teologicamente poderia significar até uma blasfêmia, mas isso é assunto para os especialistas da área.

Enfim, lembremos de uma afirmação contundente e esclarecedora de Harold Lasswell: "Pelo uso de palavras e gestos sancionados, a elite extrai sangue, impostos e aplausos das massas" ${ }^{29}$. Essa elite, tanto pode ser de direita quanto de esquerda, de centro-direita, centro-esquerda ou mesmo de algo típico do Brasil, um fenômeno chamado "Centrão".

De todos os atores mencionados, quer na Política, quer na Religião ou na união de ambas, observam-se performances, atitudes pragmáticas, discursos cênicos em busca de adesão. No entanto, após as eleições o credo do credo do eleitor não terá o mesmo valor, pois o que prevalecerá serão as relações reais de poder, e no fim das contas, é como disse Lasswell: "A linguagem da Política é a linguagem do Poder".

\footnotetext{
${ }^{27}$ Folha de S. Paulo: "João Paulo $2^{\circ}$ diz a presidente que quer vir ao Brasil em 2001". Do enviado especial a Roma (ELS) (https://www1.folha.uol.com.br/fsp/brasil/fc2011199905.htm).

${ }^{28}$ Folha de S. Paulo, 02/05/1993, Seção Teoria e Debate.

${ }^{29}$ Lasswell, Harold. A Linguagem da Política.
} 


\section{CONSIDERAÇÕES FINAIS}

Vale dizer, que a educação pragmatista se estenderia para a conduta do indivíduo em todas as esferas da vida. O otimismo de James (1911 e 1979), nesse aspecto, era tal que ele esperava que o educando se tornasse habilitado a portar-se adequadamente em qualquer circunstância da existência, afirmando que aquele que "recebe uma verdadeira educação é capaz, na prática, de sairse muito bem de situações em que se não tenha antes encontrado" (JAMES, 1911, p. 18). E afirma ainda, especificamente em relação à educação inglesa, que "um gentleman é um feixe de reações especiais, uma criatura que possui, prévia e claramente traçada, linha de conduta para todas as circunstâncias da vida" (JAMES, 1911, p. 20).

Nesse bojo, acrescentam-se as descobertas científicas que, quando obras do pragmatismo educacional, são valorizadas e incentivadas de acordo com a sua aplicação e com o lucro que proporcionarem. A obtenção de lucro não é algo injusto, porém, os meios para fazê-lo devem sê-lo, de tal forma que a tese de Maquiavel, de que os fins justificam os meios, e que "nas ações de todos os homens, máxime dos príncipes, o que importa é o êxito bom ou mau", que não é necessariamente próprio do Pragmatismo, mas que se constitui numa tese política, cuja linguagem, como afirmou Harold Lasswell, é a linguagem do poder. Isto é, os atores políticos parecem seguir o que escreveu Maquiavel, n'O Príncipe: eles não precisam realmente ter as virtudes que aparentam, basta que pareçam ser piedosos, pois o vulgo, que é a maioria, contenta-se com a aparência.

Considerando-se esta situação, é inegável que, com o passar do tempo, o Pragmatismo assumiu um papel irreversível em nossa cultura, fortalecendo a visão utilitária, isto é, instrumental, do conhecimento. Porém, o nosso pensamento não pode permanecer no sono dogmático, posto que deve ser despertado para a transformação dessa visão utilitária, desde que numa visão crítica do conhecimento e da Educação, dando o passo de volta ao lema do esclarecimento enunciado por Kant: "Tem coragem de servir-te de teu próprio entendimento", o qual está na base da "Educação para a Emancipação", defendida por Adorno em sua obra homônima. 
Conforme a caminhada deste percurso conceitual nos mostrou, podemos observar que o Pragmatismo pode ser interpretado tanto de forma positiva quanto negativa, isto é, quando o conhecimento e as técnicas são vistos como meios de lucro e de domínio. Por outro lado, verificamos também que pode haver uma interpretação positiva do Pragmatismo, se mantivermos a ética da reverência pela vida.

Infelizmente a instrumentalização chegou à Educação e à Ciência, e os atores políticos são pragmáticos pela natureza de seu ofício, pois Política é ação. Vimos que a visão pragmática da realidade chegou até à Religião, a qual, apesar de ter sido tratada como fonte de lucro desde os tempos antigos, no Capitalismo isso é feito até de forma imoral, negando o que Paulo ensinou no I Século, isto é, que "grande fonte de lucro é a piedade, com contentamento" (I TIMÓTEO, 6:6).

Enfim, a Religião foi instrumentalizada pelos atores políticos, com honrosas exceções, e chegamos, assim, ao que Marx denunciou no Séc. XIX:

\begin{abstract}
Chegou, enfim, a época em que tudo aquilo que os homens tinham considerado como inalienável tornou-se objeto de troca, de tráfico, e podia ser alienado. É a época em que as próprias cousas que, até então eram transmitidas, mas jamais trocadas; dadas, mas jamais vendidas; ganhas, mas jamais compradas - virtude, amor, opinião, ciência, consciência etc. - tudo passou enfim para o comércio. É a época da corrupção geral, da venalidade universal ou, para falar em termos de economia política, a época em que todas as cousas, morais ou físicas, tornando-se valores venais, são levadas ao mercado para serem apreciadas pelo seu mais justo valor ${ }^{30}$.
\end{abstract}

Cabe a nós o exercício da crítica e a busca do esclarecimento, para que não caiamos numa forma de Pragmatismo absoluto, uma espécie de mercantilização da razão, a qual pode ser vista na afirmação do empresário Beto Sicupira, parecida com um epitáfio da razão: "As pessoas valem pelo que elas são capazes de fazer e não por aquilo que elas conhecem. Algumas pessoas sabem tudo, mas não conseguem transformas isso em nada" ${ }^{31}$.

Diante dessa afirmação, é preciso retornar a Kant e ao Lema do Esclarecimento: "Tem coragem de servir-te de teu próprio entendimento".

\footnotetext{
${ }^{30}$ Karl MARX, Miséria da Filosofia, Cap. I. In: marxists.org (acesso em 18/05/2020).

${ }^{31}$ Citado por Anandsing Dwarkasing. Empreender na Vida. Palestra feita na UEMG - Frutal: 03/05/2019.
} 


\section{REFERÊNCIAS}

ABBAgnano, N. \& VISALBERGHI, A. História da Pedagogia. Vol. 2. Lisboa: Livros Horizonte, s./d.

BíBLIA SAGRADA. Versão Almeida Revista e Atualizada. Sociedade Bíblica do Brasil. Disponível em: https://www.bibliaonline.com.br/ara. Acesso em 16/05/2020.

CHILDS, John L. Pragmatismo y Educación; su interpretación y crítica. Buenos Aires: Nova, 1956.

COSTA, João Cruz. Panorama da História da Filosofia no Brasil. S. Paulo: Cultrix, 1960.

HESSEN, J. Teoria do Conhecimento. S. Paulo: Martins Fontes, 1999.

JAMES, William. Palestras Pedagógicas. (1911).

JAMES, William. Pragmatismo: textos selecionados. S. Paulo: Abril, 1979 (Coleção "Os Pensadores").

KANT, Immanuel. Resposta à Pergunta: o que é Esclarecimento?. In: Textos Seletos. 3. ed. Petrópolis: Vozes, 2005.

LASSWELL, Harold. A Linguagem da Política. Brasília: Ed. da UNB, s/d.

MARX \& ENGELS. A Ideologia Alemã. 7. ed. S. Paulo: Hucitec, 1989.

MAQUIAVEL, Nicolau. O Príncipe. S. Paulo: Abril, 1979 (Coleção "Os Pensadores").

PÁDUA, Marsílio de. O Defensor da Paz. Petrópolis: Vozes, 1997.

MARX, Karl. Miséria da Filosofia. Disponível em: marxists.org. Acesso em 18/05/2020.

RYAN, Frank X. et alii. The Real Metaphysical Club. New York: State University of New York, 2019. Disponível em: books.google. Acesso em 16/05/2020.

SCHINZ, Albert. Anti-pragmatisme: examen des droits respectifs de l'aristocratie intelectuelle et de la democratie sociale. Paris: Felix Alcan, 1909.

SPIRITO, Ugo. El Pragmatismo en la Filosofía Contemporánea. Buenos Aires: Losada, 1945.

\section{Jornais, Revistas e Sites consultados}

Folha de S. Paulo. "João Paulo $2^{\circ}$ diz a presidente que quer vir ao Brasil em 2001". em: https://www1.folha.uol.com.br/fsp/brasil/fc2011199905.htm. Acesso em 18/05/2020.

Folha de S. Paulo. Seção: Teoria e Debate. Edição de 02/05/1993. 
O GLOBO - Abraham Weintraub (Suplemento "Sociedade", de 25/04/2020). Ministro dá dica para o Enem: Questões ideológicas, muito polêmicas, não devem acontecer esse ano. Disponível em: https://oglobo.globo.com/sociedade/ministro-da-dica-para-enem-questoesideologicas-muito-polemicas-nao-devem-acontecer-esse-ano-23623156. Acesso em 20/05/2020, às 10h13min.

PORTAL G1. Faculdade oferece prêmio em dinheiro ao aluno que tirar boa nota no Enade. Disponível em: http://g1.globo.com/Noticias/Vestibular/0,,MUL176482-5604,00-

FACULDADE+OFERECE+PREMIO+EM+DINHEIRO+AO+ALUNO+QUE+TIRA R+BOA+NOTA+NO+ENADE.html, de 10/11/2007. Acesso em 17/05/2020.

Jornal da Gazeta (12/10/2018). Reportagem: "Em campanha, Haddad vai à missa na periferia". Disponível em: https://www.youtube.com/watch?v=AMK7L72N5C0. Acesso em 18/05/2020.

Revista Exame Edição de 26/04/2019. Disponível em: https://exame.abril.com.br/brasil/bolsonaro-sugere-reduzir-verba-para-cursosde-filosofia-e-sociologial. Acesso em 17/05/2020.

Vídeo: Bispa Sonia pregando, é aula de teatro. Disponível em: https://www.youtube.com/watch?v=pl-biB2AJoA. Acesso em 18/05/2020. 